\title{
Performance of polyaniline nanofibers (PANI NFs) as PANI NFs-silver (Ag) nanocomposites (NCs) for energy storage and antibacterial applications
}

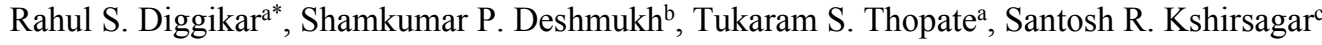
$\mathrm{a}^{*}$ Department of Chemistry and Research Centre, New Arts, Commerce And Science College, Parner, District- Ahmednagar, Maharashtra, INDIA

${ }^{b}$ Department of Chemistry,D.B.F. Dayanand College of Arts and Science, Solapur, Maharashtra, INDIA 'Department of Chemistry, R.B.N.B. College, Shrirampur, District- Ahmednagar, Maharashtra, INDIA

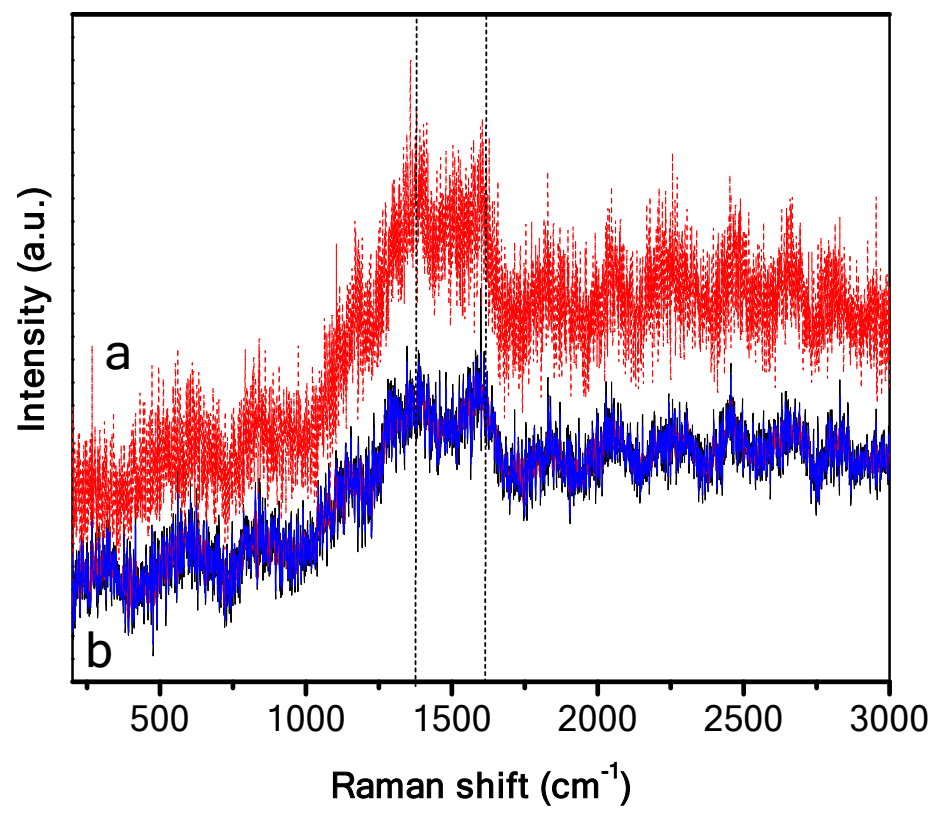

Figure S1: Raman study of (a) $\mathrm{HCl}$ and (b) $\mathrm{HNO}_{3}$ doped PANI NFs

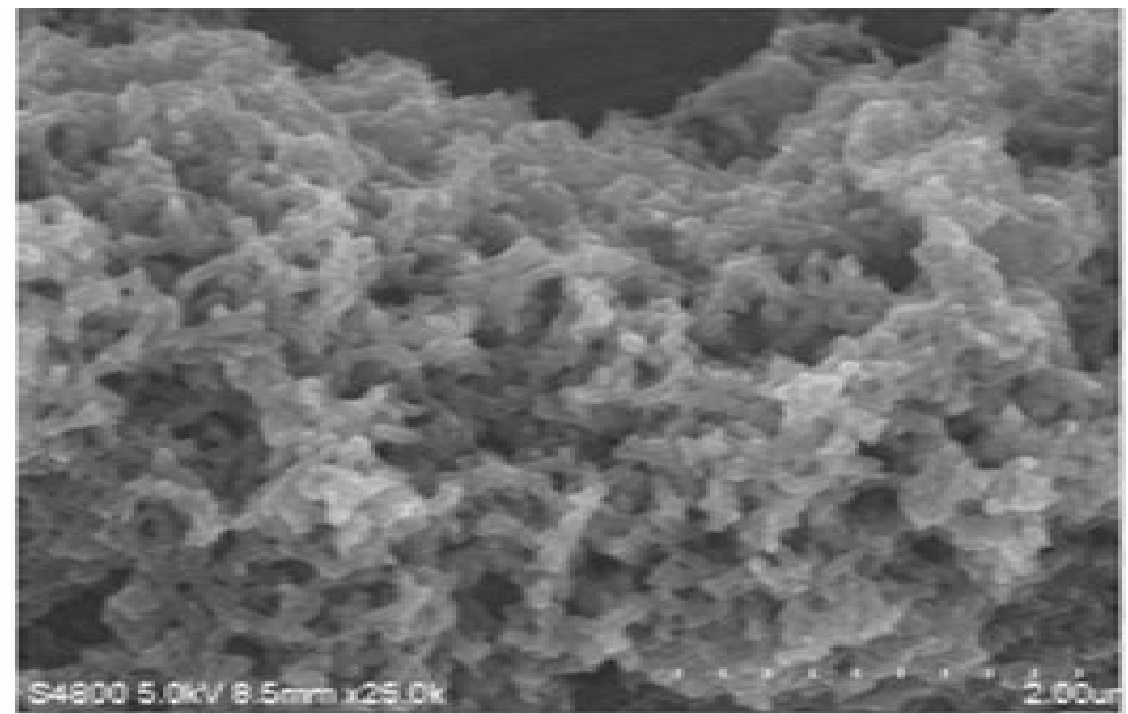

Figure S2: FESEM images of $\mathrm{HCl}$ doped PANI-NFs 


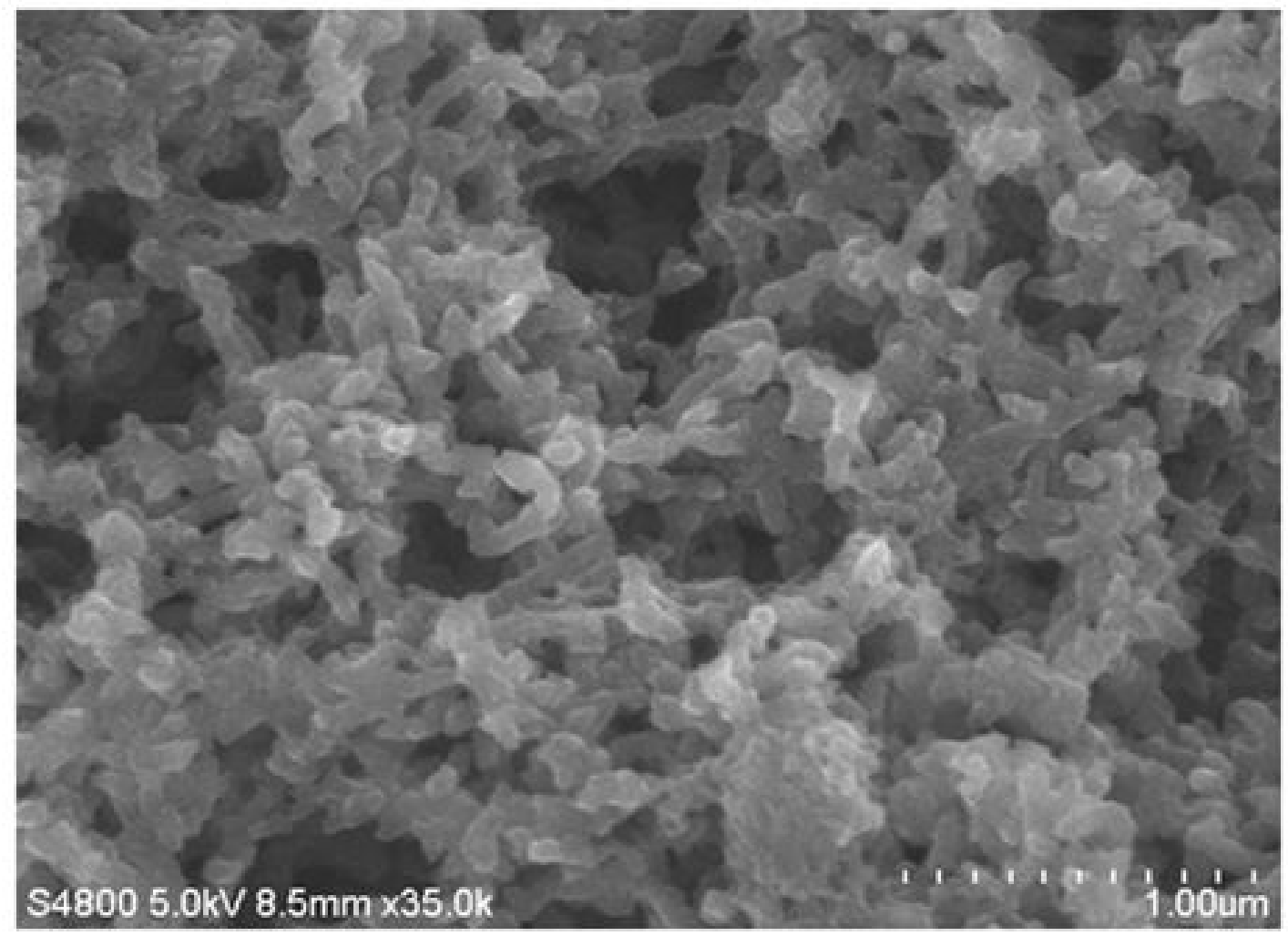

Figure S3: FESEM image of $\mathrm{HNO}_{3}$ doped PANI-NFs

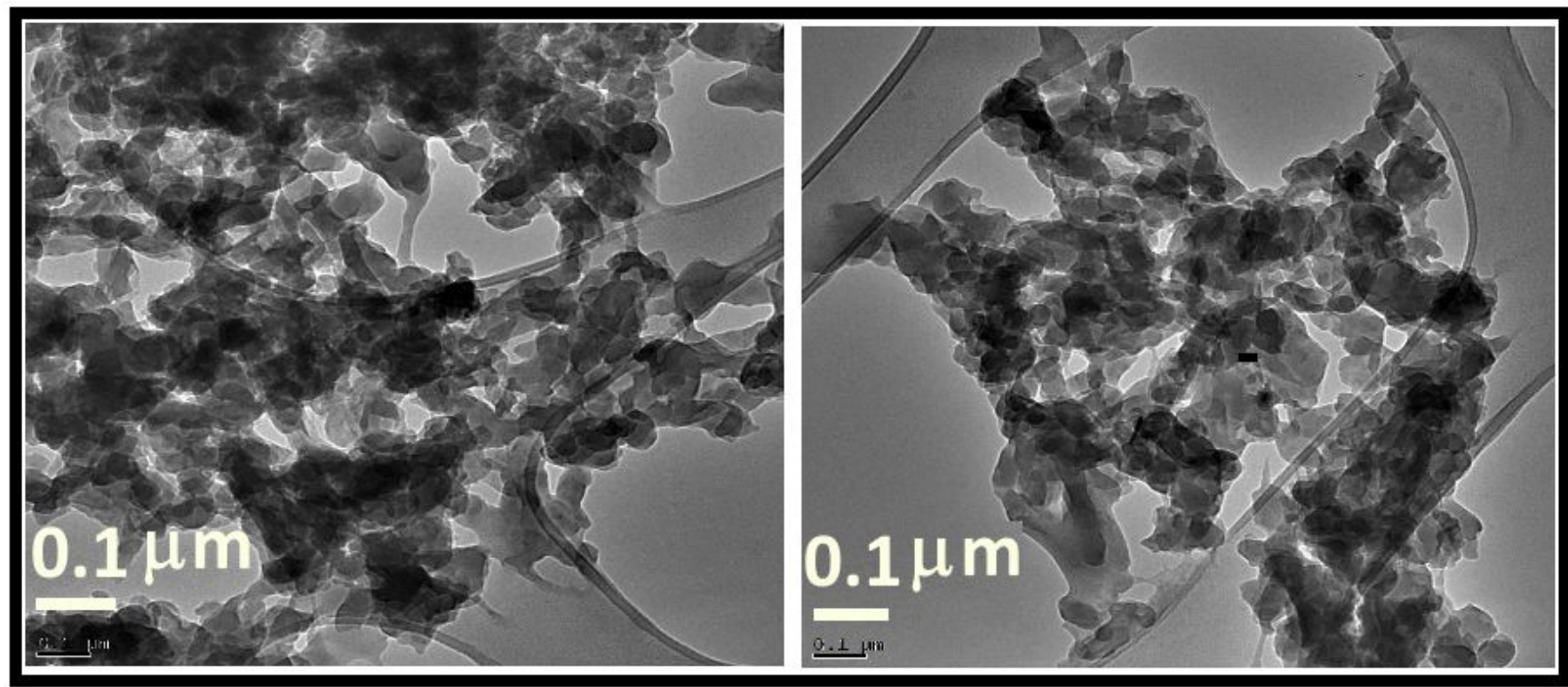

Figure S4: TEM images of $\mathrm{HCl}$ doped PANI-NFs 


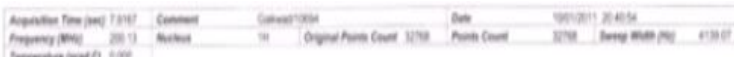

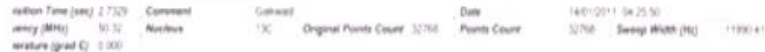

(a)

(d)
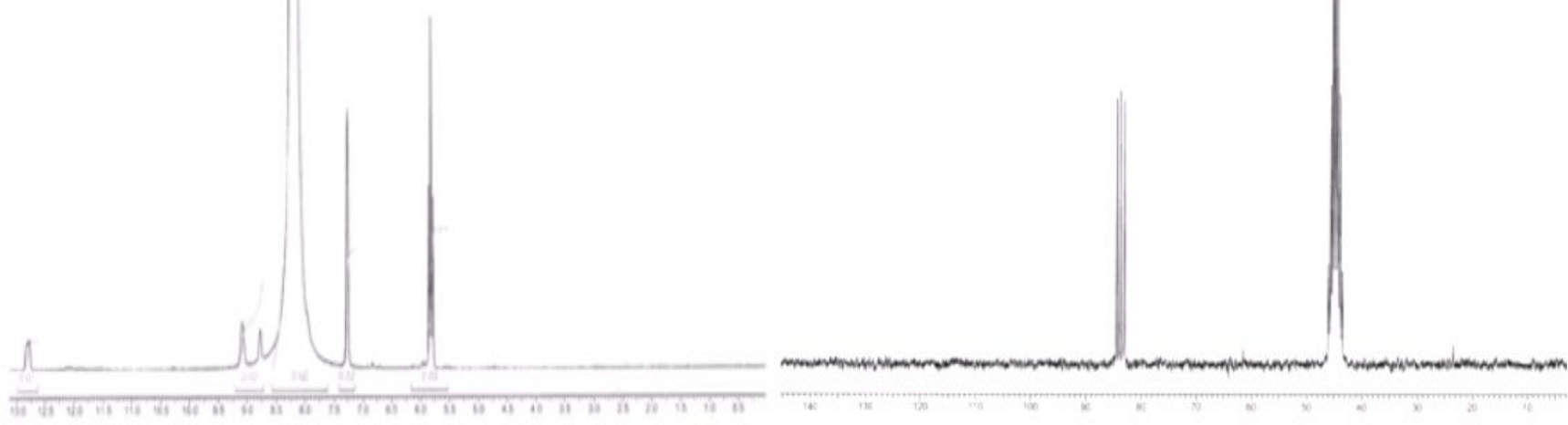

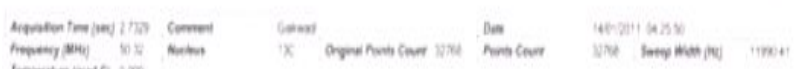

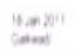

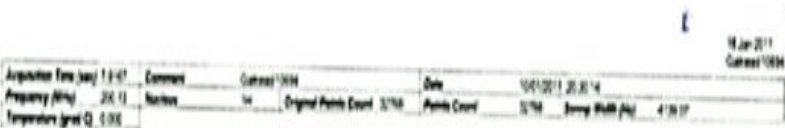

(b)

(e)
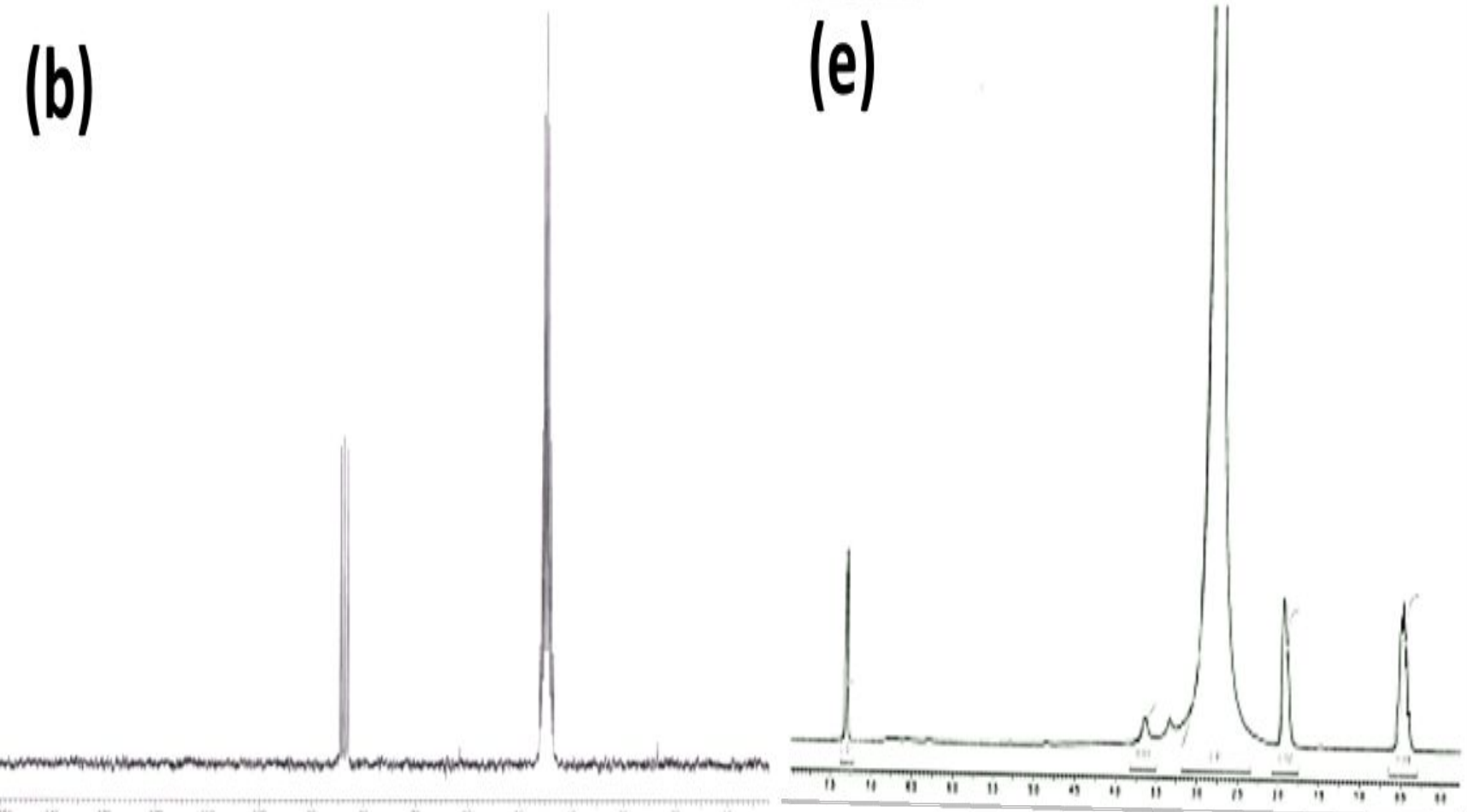


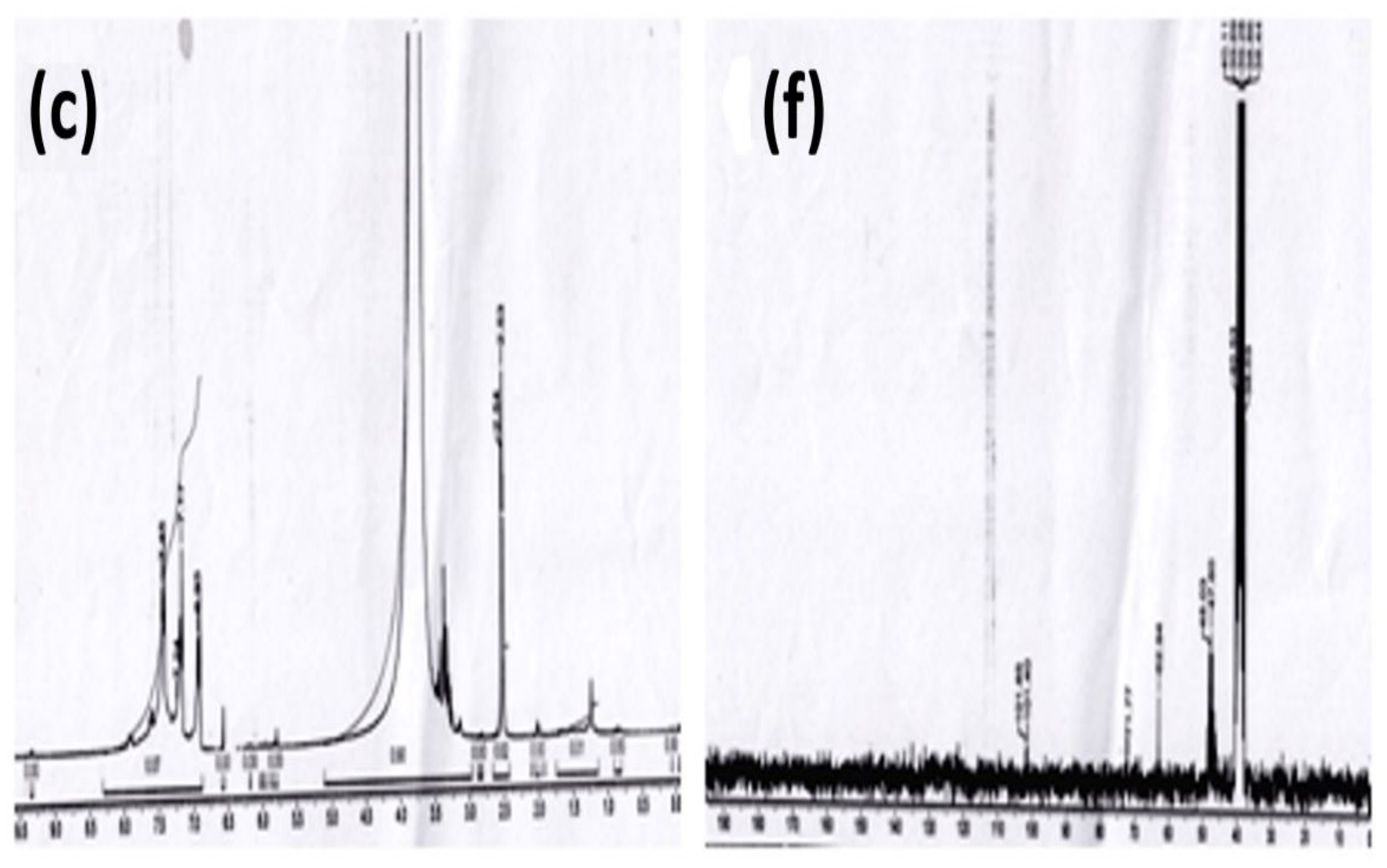

Figure S5: Figure S5 (a \& d) describes the ${ }^{1} \mathrm{H}$ NMR and ${ }^{13} \mathrm{C}$ NMR of $\mathrm{HCl}$ doped PANI NFs, Figure S5 (b \& e ) describes the ${ }^{1} \mathrm{H}$ NMR and ${ }^{13} \mathrm{C}$ NMR of $\mathrm{HNO}_{3}$ doped PANI NFs and Figure S5 (c \& f) describes the ${ }^{1} \mathrm{H}$ NMR and ${ }^{13} \mathrm{C}$ NMR ST-PANI NSs in dimethyl sulfoxide (DMSOd6) and tetra methyl silane (TMS)

Nuclear Magnetic resonance spectroscopy is useful to know the behavior of certain atomic nuclei, namely those which have magnetic moments arising from their spin in the presence of applied magnetic fields. The applied field is responsible for the splitting up of nuclear energy levels between which transitions may be caused by absorption of suitable electromagnetic radiation. The sensitivity of NMR method depends primarily upon the strength of nuclear magnet. It is also affected by certain experimental variables. It is observed that only aromatic ring protons around 7-7.5 ppm appeared \& $\mathrm{NH}$ protons disappeared which are involved in the polymerization. The crystallinity and orientation of conducting polymer are of much interest, because the more highly ordered systems could display a silver conductive state. ${ }^{1-10}$

In Figure S5a, major peaks of the $\mathrm{HCl}$ doped PANI NFs have chemical shifts at 8.5-7.58ppm $(\mathrm{m} 10 \mathrm{H})$ for aromatic rings, 7.6-7.1 $(4 \mathrm{H})$ for delocalized conjugate aromatic ring, $6.27(1 \mathrm{H})$, and $5.72 \mathrm{ppm}(1 \mathrm{H})$. The $1 \mathrm{H}$ signals with chemical shifts at $7.0-8.5 \mathrm{ppm}(14 \mathrm{H})$ are associated with protons directly bonded to aromatic rings. Since, the observed chemical shifts are all < $5.9 \mathrm{ppm}$; each aromatic ring may be directly bonded to amines. The sharp peaks at 6.27 and $5.72 \mathrm{ppm}$ are characteristic of $\mathrm{HCl}$ doped PANI NFs. It is not certain that these peaks can be readily assigned to $\mathrm{N}-\mathrm{H}$. The primary amine groups $\left(-\mathrm{NH}_{2}\right)$ easily form hydrogen bonding thus usually have broad peaks. The secondary amine groups (-NH-), when connected to two aromatic rings, usually have a high chemical shift ( $>8 \mathrm{ppm})$. 
However, in spectrum ${ }^{1} \mathrm{H}-\mathrm{NMR}$ of $\mathrm{HCl}$ doped PANI NFs the signal at $8.7 \mathrm{ppm}$ was assigned to hydrogen of hydrochloric acid groups. The integrals of hydrogen of hydrochloric acid and methyl signals are in the ratio $\mathrm{HCl} / \mathrm{HCH}_{3}=8.2 / 8.83=0.92$ indicating that $92 \%$ of hydrochloric acid was used in the reaction. ${ }^{1}$

Figure $\mathrm{S} 5 \mathrm{~d},{ }^{13} \mathrm{C}$ NMR spectra are surprisingly clean, considering that the $\mathrm{HCl}$ doped PANI NFs is a mixture of different oxidation states. The simplicity of the carbon lines suggests that the major components (tetramers) have symmetric structures. The ${ }^{13} \mathrm{C}$ lines at $80.2-80.4 \mathrm{ppm}$ correspond to carbons connected to the protons with chemical shifts of 5.72 and $6.27 \mathrm{ppm}$, respectively. ${ }^{2}$ High intensity peak at $45.5 \mathrm{ppm}$ indicates PANI NFs in presence of acidic medium. The two peaks with very high chemical shifts may correspond to carbon atoms connected to the phenazinium nitrogen.

Figure S5b, signals appear at $0.5 \mathrm{ppm}$ and $2.00 \mathrm{ppm}$ are attributed to hydrogen resonances of DMSO-d6 (solvent) and water molecules respectively, which are difficult to eliminate from the PANI NFs. Figure S5e, the signals centered at $3.5 \mathrm{ppm}$ and $7.25 \mathrm{ppm}$ was assigned to the resonances of the hydrogen amine and aromatic hydrogen, respectively. The integral signals of hydrogen methyl and aromatics are in the ratio of $\mathrm{HNO}_{3} / \mathrm{H}$ aromatic $=25.52 / 29.03=0.87$ indicating that $87 \%$ of nitric acid were used in the reaction supported by Wolter et al. ${ }^{3}$

The ST-PANI NSs product obtained at the early stages of aniline polymerization by the oxidation of aniline with APS was also analyzed by NMR. Relevant parts of ${ }^{1} \mathrm{H}$ NMR spectra of the products collected are shown in Figure S5c. The spectra does not contain the very broad signals of NH protons, which appear in the range 8.0-6.5 ppm and could not give much information about the same. As clearly seen, the spectra are virtually the same, differing only in the width of the signals and in some cases the broadening being probably observed by some higher-molecular-weight components. The major part of the NMR detectable products is identical or at least closely analogous in accordance with the results of the earlier FTIR spectroscopic characterization. This was explained by the easy oxidation of neutral aniline molecules to oligomers which preferentially takes place even in acidic media where the concentration of aniline molecules is low. ${ }^{4}$ The similar oxidation of anilinium cation is much more difficult and proceeds only later during the subsequent polymerization.

In conclusion, using various ${ }^{1} \mathrm{H},{ }^{13} \mathrm{C}-\mathrm{NMR}$ spectra of PANI NFs and ST-PANI NSs, we have shown that the products of early stages of oxidative aniline polymerization have quite analogous structures irrespective of the polymerization time, kind and concentration of the added acid. In addition to the expected oligomeric chains with intermittent diamine and S4 quinoneimine moieties, which are only partly detected by NMR with broad signals, a markedly populated and hitherto not described oxygen-containing quinoneimine group was also detected. It destroys the chain conjugation needed for the conductivity of product. In Figure S5f, the integral signals of hydrogen methyl and aromatics ratio indicates the minimum doping of acid in ST-PANI. This fact is further supported by our conductivity measurements. It is clear from ${ }^{1} \mathrm{H}$ NMR and ${ }^{13} \mathrm{C}$ NMR study, the $\mathrm{HCl}$ is more preferable for polymerization of aniline as well as enhancement of conductivity which is ultimately responsible for behavior of silver-PANI nanocomposite synthesized by post polymerization. ${ }^{10-14}$ 


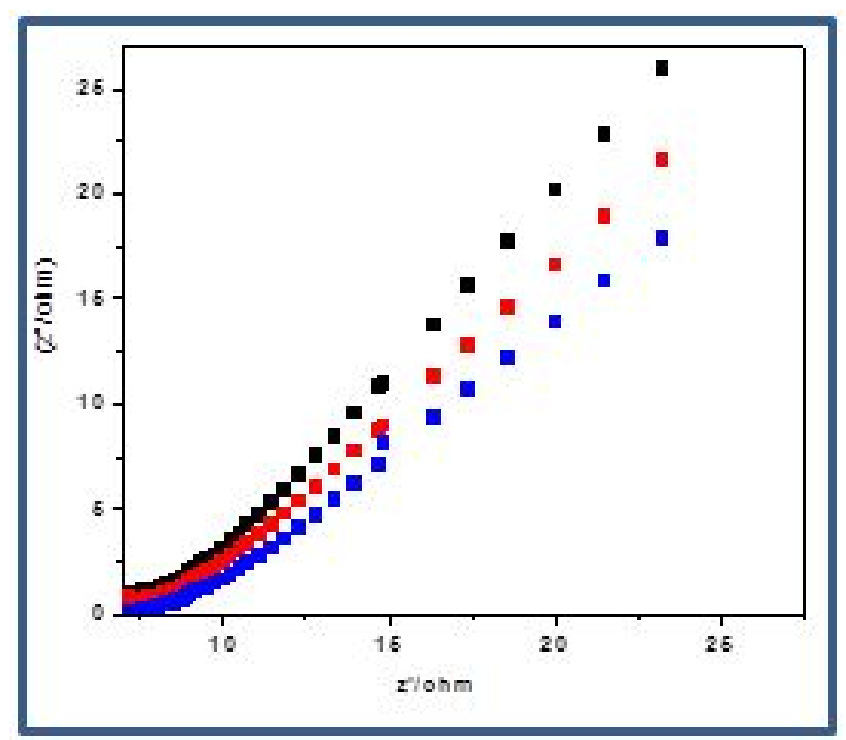

Figure S6: EI data of $\mathrm{HCl}$ doped PANINFs behaving PANI NFs -silver NCs (Black), $\mathrm{HNO}_{3}$ doped PANI NFs (Red), and ST-PANI NSs (Blue)

Table S1: Conductance and specific conductance* (*Values of specific capacitance are irrespective of electrolyte)

\begin{tabular}{|l|l|l|l|l|}
\hline $\begin{array}{l}\text { Sr. } \\
\text { No }\end{array}$ & Type of PANI NFs & $\begin{array}{l}\text { Conductivity } \\
\left(\mathbf{S ~ c m}^{-1}\right)\end{array}$ & $\begin{array}{l}\text { Specific capacitance } \\
(\mathbf{F g - 1}) \mathbf{( 5 0 m V s - 1 )}\end{array}$ & Ref. \\
\hline 1 & HCl doped PANI NFs & 48.47 & 570 & $\begin{array}{l}\text { Presented } \\
\text { work }\end{array}$ \\
\hline 2 & HNO 3 doped PANI NFs & 32.08 & 320 & $\begin{array}{l}\text { Presented } \\
\text { work }\end{array}$ \\
\hline 3 & PANI NSs & 11.9 & 270 & $\begin{array}{l}\text { Presented } \\
\text { work }\end{array}$ \\
\hline 4 & $\begin{array}{l}\text { Silver vanadium oxide -PANI } \\
\text { NCs }\end{array}$ & - & 365.5 & 20 \\
\hline 5 & $\begin{array}{l}\text { Silver vanadium sulfide- PANI } \\
\text { NCs }\end{array}$ & & 440 & 21 \\
\hline 6 & PANI NFs & $2-10$ & 122 & 35 \\
\hline 7 & PANI nonfibrillar & - & 33 & 35 \\
\hline
\end{tabular}

\section{References for NMR study}

1. Umadevi, G.; Ponnusamy, V.; Paramsivam, M.;Palaniswamy, S.; Electrochemical Synthesis And Characterization $\mathrm{Of}_{2} \mathrm{SO}_{4}$ Doped Aniline. Rasayan J. Chem. 2010, 194-200.

2. Haigh, C.W.; Annual reports of NMR spectroscopy. Academic press, 1971, 311.

3. Wolter, A.; Rannou, P.; Travers, J. P.; Model for aging in HCl-protonated polyaniline: Structure, conductivity, and composition studies Phys. Rev.1998, 58, 7637-7647. 
4. Stejskal, J.; Sapurina, I.; Trchova, M.; Konyushenko, E. N.; Oxidation of Aniline: Polyaniline Granules, Nanotubes, and Oligoaniline Microspheres.Macromolecules 2008, 41(10), 3530-3536.

5. Mbhele, Z.M.; Sakmane, M.G.; VanSittert, C.G.C.E.; Nedeljkovic, J.M.; Djokovic, V.; Luyt, A.S.; Fabrication and Characterization of Silver-Polyvinyl Alcohol Nanocomposites.Chem. Mater.2003, 15(26), 5019-5024.

6. Kowalewski, V.J.; Progress in NMR spectroscopy. Pregamon Press, 1969; pp 1-31.

7. Dutta, M.; Nuclear Magnetic resonance spectroscopy. IVY publication, 2000.

8. Sanchez, C. O.; Bustos, C. J.; Carey, M.L. D. A.; Effect of electron-withdrawing type substituents in the polyaniline ring on the electrical conductivity.Polym. Bull., 2005, $54,263-270$.

9. Schechter, D.; Mitchell, S.; Schmitt, R.;Xiong, J.; 30 ${ }^{\text {th }}$ Annual Meeting of the Controlled Release Society. Glasgow, Scotland, 2003, 19-23.

10. Shinde, S. D.; Jayakannan, M.; Probing the Molecular Interactions at the Conducting Polyaniline Nanomaterial Surface via a PyreneFluorophore.J. Phys. Chem. C, 2010, $114,15491-15498$.

11. Zhang, X.;Goux, W. J.; Manohar, S. K.; Synthesis of Polyaniline Nanofibers by "Nanofiber Seeding". J. Am. Chem. Soc.2004, 126, 4502-4503.

12. Mosqueda, Y.;Pe'rez-Cappe, E.;Aranab, J.; Longo, E.;Ries, A.;Cilenseb,; Nascente P.A.P., M.;Arandad, P.; Ruiz-Hitzky, E.; Preparation and characterization of $\mathrm{LiNi}_{0.8} \mathrm{Co}_{0.2} \mathrm{O}_{2} / \mathrm{PANI}$ microcomposite electrode materials under assisted ultrasonic irradiation.J. Solid State Chem.,2006, 179(1),308-314.

13. Heinze, J.; Frontana-Uribe, B. A.; Ludwigs S.; Electrochemistry of Conducting Polymers-Persistent Models and New Concepts. Chem. Rev., 2010, 110, 4724-4771.

14. Hong, S.Y.; Park, S. M.; Electrochemistry of Conductive Polymers 40. Earlier Phases of Aniline Polymerization Studied by Fourier Transform Electrochemical Impedance Spectroscopy.J. Phys. Chem. B,2007, 111, 9779-9786 